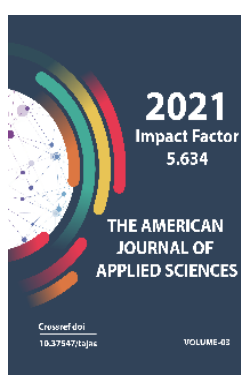

Journal Website: http://usajournalshub.c om/index,php/tajas

Copyright: Original content from this work may be used under the terms of the creative commons attributes 4.0 licence.

\section{Stability Of A Cylindrical Shell}

\author{
Shakhrukh Muratovich Davlyatov \\ Candidate Of Technical Sciences, Associate Professor, Fergana Polytechnic Institute, \\ Uzbekistan
}

\section{Khusnitdin Akhrarovich Akramov}

Doctor Of Technical Sciences, Professor, Tashkent Institute Of Architecture And Construction, Uzbekistan

\title{
ABSTRACT
}

Results of researches of stability of the cylindrical cover of circular cross section consisting of several layers at a zagruzheniye the external evenly distributed loading are given in this article. Settlement dependences are offered, critical loadings, opkredelena of a form of loss of stability of a cover are found.

\section{KEYWORDS}

Cylindrical shell, cross section, stability, critical loads, Poisson, symmetric, defect, cracks.

\section{INTRODUCTION}

The problem of stability of a hingedly supported cylindrical shell with a circular crosssection containing a longitudinal bundle is considered. The load is taken to be a uniformly distributed pressure applied to the outer surface of the shell. The general view and cross-section of the shell are shown in fig. 1. 

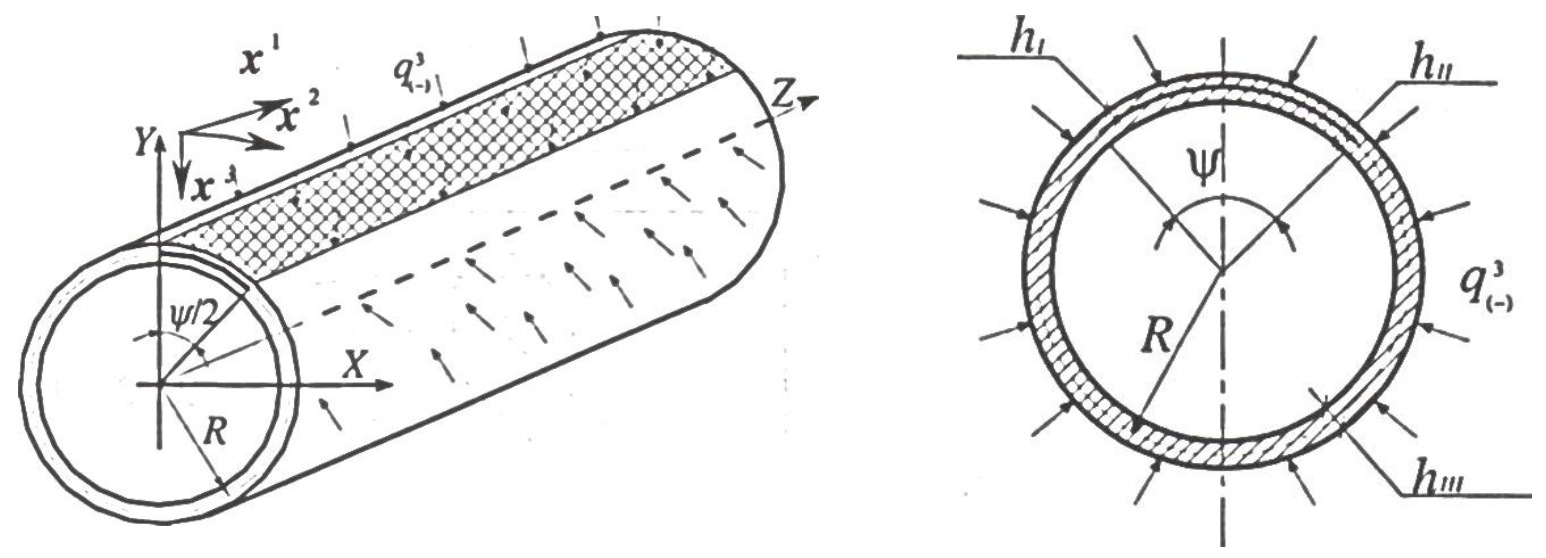

$a b$

Figure: 1. General view (a) and cross-section of a cylindrical shell with delamination (b)

Delamination divides the shell by thickness into several characteristic sections with thicknesses $h_{1} h_{\| l}, h_{\| l}$. The introduced parameter $h^{*}=h^{\prime} / h^{\prime \prime \prime}$ determines the location of the crack along the shell thickness. For a neutral surface $h^{*}=0,5$. The change in the size of the crack in the transverse direction is characterized by the parameter $\psi^{*}=\psi / \pi$. For this problem, there is a well-known solution obtained by V.P.Troshinim [1-8].

The influence of the size and location of the interlayer crack along the shell thickness on the value of the critical external pressure is investigated. The calculation of the shell was carried out with the following initial data: modulus of elasticity $E=210 \mathrm{GPa}$; Poisson's ratio $\mu-0.25$; the ratio of the radius of the middle surface of the shell to its thickness $R$ / $h_{I I I}=100$; the crack opening angle $\psi$ varied in the range from o rad to $0.754 \mathrm{rad}$; the ratio of the shell length to the radius of the middle surface was taken equal to $I / R=1 ; 2$. The ratio of layer thicknesses $h^{\prime} / h^{\text {III }}$ varied from 0.1 to 0.9 .
A fragment of the shell bounded by contour lines $x^{1}=0, x^{2}=0$ and symmetry lines $x^{1}=1 / 2, x^{2}=\pi$ was taken as a calculated one. A finite difference mesh of $15 \times 37$ nodes (15 nodes in the length direction and 37 in the $x^{1}$ direction; 20 out of 37 nodes were superimposed on the defective area) was applied to the fragment selected in this way, at which the calculation error does not exceed $3 \%$.

Calculation results for a shell with a defect located on the middle surface (see Fig. 1) in the form of dependences of dimensionless loads $q^{*}=q_{\mathrm{cr}} / q_{0}$ on the parameter $\psi^{*}=\psi / 2 \pi$, where $q_{\mathrm{cr}}$ is the critical load for a shell with a defect; $q_{0}$ is the critical external pressure for a defect-free shell with a length of $l=1 \mathrm{~m}$, which was determined by the formula:

$q_{0}=\frac{1.75 \pi E}{l R^{\frac{3}{2}}} \sqrt[4]{\frac{h_{I I I}^{10}}{12^{3}\left(1-v^{2}\right)^{3}}}[1]$. 
The calculation results were obtained without taking into account the one-sided interaction between the layers within the boundaries of the defective areas.

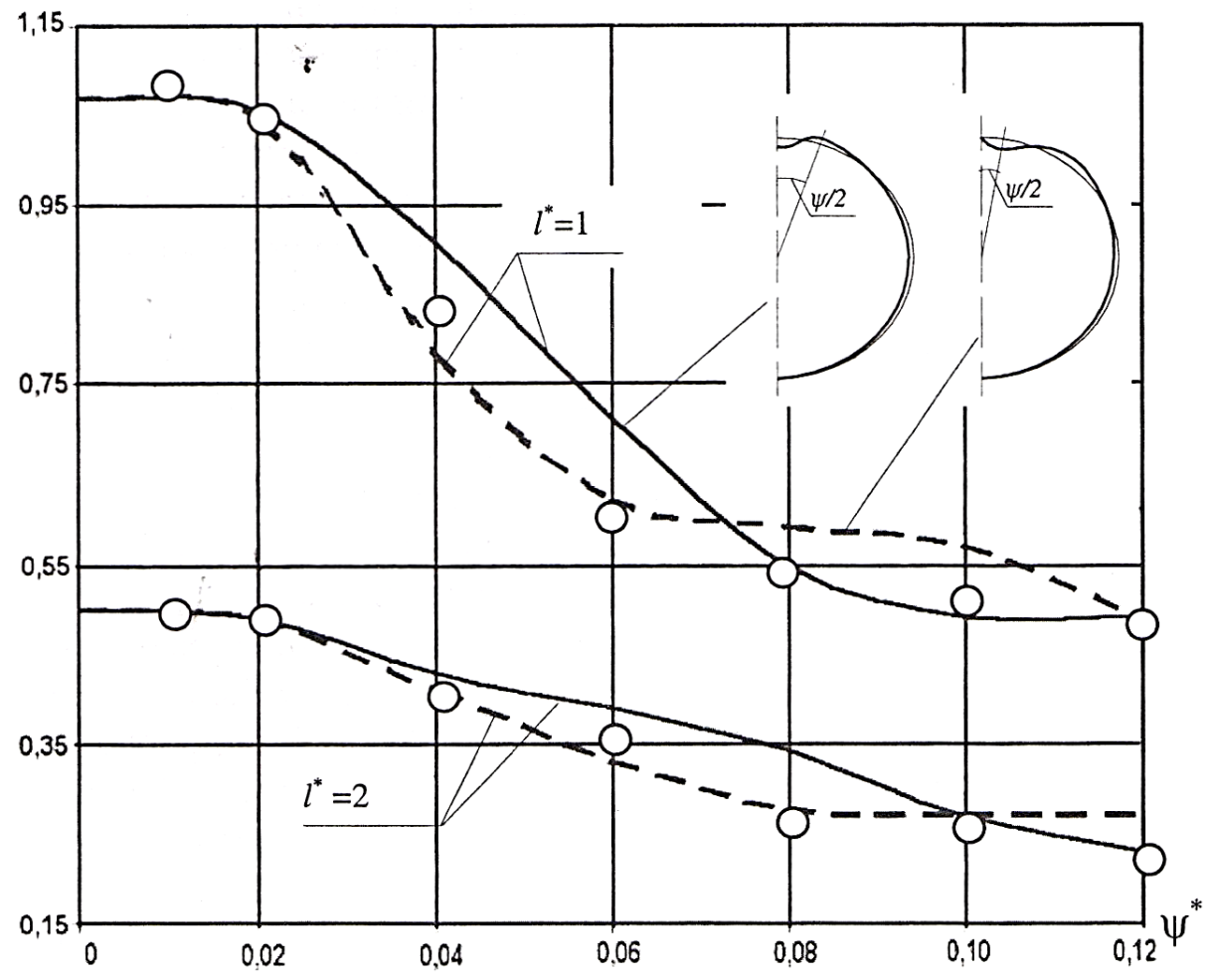

Figure: 2 . To the calculation of a cylindrical shell with a defective section (solid lines - critical loads corresponding to symmetric forms of buckling; dotted lines - the same, skew-symmetric; round markers - results obtained by the proposed method)

The performed calculation shows a good convergence of the critical load values (the maximum discrepancies do not exceed $5 \%$ ).

As seen from Fig. 2, a change in the shell length significantly affects the absolute values of the critical external pressure. However, the general character of the curves remains the same with varying the shell length. All the above dependences, when changing $\psi^{*}$ from zero to $\psi^{*}=0.015-0.02$, have a horizontal section, within which the critical parameter $q_{c r}$ remains constant. Therefore, the parameter $\psi^{*}=0.02$ determines the limiting width of the admissible bundle opening. Smaller delamination does not reduce the initial critical load. Large-sized stratifications lead to a decrease in the critical external pressure and localization of the general form of wave formation.

An analysis of buckling patterns shows that with a symmetric shape and small sizes of initial defects, crack opening can occur. Depending on the size of the delamination, alternating forms of buckling occurs symmetric and skew-symmetric. The order of changing the buckling forms can vary depending on the length of the shell.

Investigation of layers asymmetric in the thickness of the shell showed that their location near the inner surface of the shell can lead to buckling of one thin layer. With a large 
thickness of a thin layer, the shell loses its stability in mixed forms.

It should be noted that contact interactions between the layers are possible at large delamination sizes (this fact was determined from the intersection of layers when constructing forms of loss of stability).

In contrast to the general forms of buckling, the critical loads for local forms of buckling depend little on the shell length. Obviously, for shells of relatively long length, the level of the critical external pressure of a defect-free shell can be lower than the lowest value of the critical load of the local form of buckling of the shell with delamination.

The calculation showed that delamination located symmetrically from the neutral surface of the shell in the interval $h^{*}=0.35-0.65$ is equally dangerous. In the general case, the surface curvature affects the critical parameter and the size of the limiting bundles. For this reason, a delamination located closer to the inner surface of the shell reduces the critical pressure to a greater extent than a delamination closer to the outer surface.

The limiting size of the delamination is determined based on the degree of reduction in the critical load. Since in the case of a local form of loss of stability one should expect instability of only one thin layer, the loss of stability of the entire shell in this case does not occur (provided that the separation does not propagate). Consequently, the limiting dimensions of the delamination found on the basis of the local form of buckling are not restrictions on the bearing capacity.

In the development of the research, an analysis of the stability of a hingedly supported three-layer cylindrical shell with a defect in the central part located between the inner bearing layer and the filler was carried out (Fig. 3).

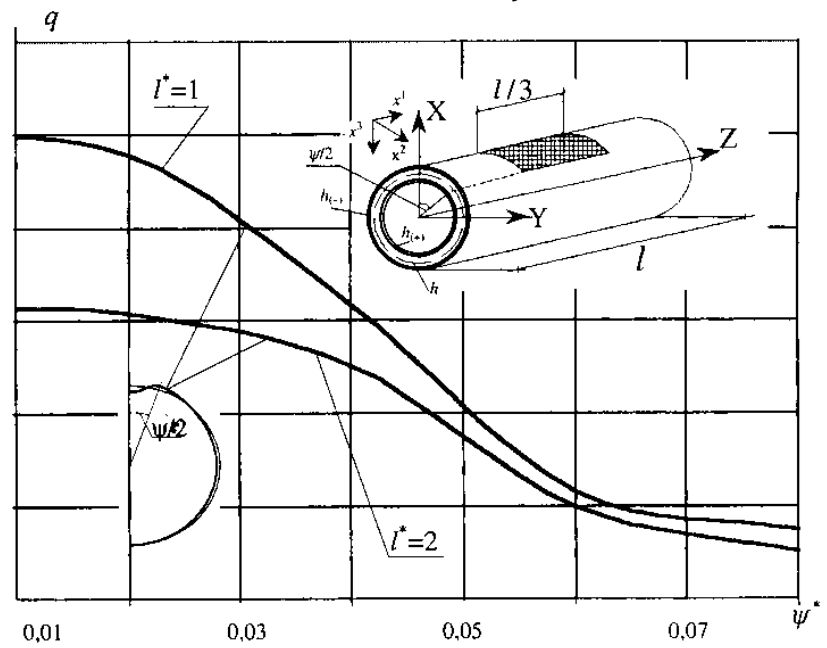

Figure: 3. To the calculation of the stability of a three-layer cylindrical shell with a defect in the central part

The shell was loaded with a uniformly distributed pressure applied to the outer surface of the carrier layer. The part of the shell bounded by lines along the $x^{1}=0, x^{1}=1 / 2$ axis and by symmetry lines in the $x^{2}=0, x^{2}=\pi$ direction was taken as the calculated fragment. 
The following parameters were taken as the initial ones: the modulus of elasticity of the bearing layers $E( \pm)=210 \mathrm{GPa}$; the modulus of elasticity of the filler $E=2.10 \mathrm{GPa}$; Poisson's ratio for all three layers is taken $v( \pm)=v=0,25$. The thickness of the outer bearing layer $h(-$ ) $=0.002 \mathrm{~m}$, the filler $\mathrm{h}=0.018 \mathrm{~m}$, the inner layer $h(+)=0.001 \mathrm{~m}$. The ratio of the radius of the middle surface of the three-layer shell to the thickness of the three-layer package $R / H=100$; the size of the defect $\psi$ in the direction of the $\mathrm{x} 2$ axis varied in the range from $0.1 \mathrm{rad}$ to 0.754 rad; the ratio of the length of the shell to the radius of the middle surface is $1 / K=1: 2$.

As a result of the calculation, the critical loads were found, the forms of buckling were determined.

The main results of the calculation (see Fig. 3) in the form of the dependence of the dimensionless value of the critical load $q^{*}=\left[\begin{array}{ll}q_{c r} /(E & ( \pm)\end{array}\right] 10^{6}$ on the parameter $\psi^{*}=\psi /(2 \pi)$. The typical form of loss of stability is also shown here. The resulting critical loads correspond to symmetric buckling patterns.

It was found that a change in the size of a defect in the direction of the $x^{2}$ axis in the range from $\psi^{*}=0.01-0.015$ does not reduce the critical load. Defect opening angles exceeding $\psi^{*}=0.015$ lead to a decrease in the critical load and localization of the general form of buckling of a three-layer cylindrical shell.

The results of studies of the stability of a cylindrical shell of circular cross-section, consisting of several layers when loaded with an external uniformly distributed load, made it possible to establish the actual operation of the shell. The proposed calculated dependences give good convergence of the found critical loads, made it possible to determine the forms of buckling of the shell and can be used in practical calculations.

\section{REFERENCES}

1. Davlyatov S. M., Makhsudov B. A. Technologies for producing high-strength gypsum from gypsum-containing wastes of sulfur production-flotation tailings //ACADEMICIA: An International Multidisciplinary Research Journal. - 2020. - T. 10. - №. 10. - C. 724-728.

2. Muratovich D. S., Shavkatovich N. K. Influence of Changes In Microclimate Parameters On Human Well-Being And Operational Characteristics of Building Structures //The American Journal of Engineering and Technology. - 2020. - T. 2. - №. 11. - C. 113-117.

3. Akhrarovich A. K., Muradovich D. S. Calculation of cylindrical shells of tower type, reinforced along the generatrix by circular panels //European science review. - 2016. - №. 3-4.

4. Adilhodzhaev A. et al. THE STUDY OF THE INTERACTION OF ADHESIVE WITH THE SUBSTRATE SURFACE IN A NEW COMPOSITE MATERIAL BASED ON MODIFIED GYPSUM AND TREATED RICE STRAW //European Journal of Molecular \& Clinical Medicine. - 2020. - T. 7. - №. 2. - C. 683-689.

5. Muratovich D. S. Study of functioning of reservoirs in the form of cylindrical shells //European science review. - 2016. - №. 910.

6. Muratovich D. S., Shavkatovich N. K. Influence Of Changes In Microclimate Parameters On Human Well-Being And Operational Characteristics of Building Structures //The American Journal of 
Engineering and Technology. - 2020. - T.

2. - №. 11. - C. 113-117.

7. Goncharova N.I., Abobakirova Z.A., Mukhamedzyanov A.R. ENERGY SAVING

IN THE TECHNOLOGY OF ENCLOSING STRUCTURES // Energy and resource saving technologies and equipment in the road and construction industries. - 2020 .p. 107-112.

8. Goncharova N. I., Abobakirova Z. A., Kimsanov Z. Technological Features of Magnetic Activation of Cement Paste " Advanced Research in Science //Engineering and Technology. - 2019. - Vol. 6. - No. 5 . 